\title{
Health Information Science and its growing popularities in Indian self financed universities: Emphasizing Private Universities-A Study
}

\author{
P. K. Paul ${ }^{1 *}$, P. S. Aithal ${ }^{2}$, A. Bhuimali ${ }^{3}$ \\ ${ }^{1 *}$ Raiganj University (RGU), West Bengal, India \\ ${ }^{2}$ Vice Chancellor, Srinivas University, Karnataka, India \\ ${ }^{3}$ Vice Chancellor, Raiganj University (RGU), West Bengal, India \\ ${ }^{1 *}$ Corresponding Author: pkpaul.infotech@gmail.com
}

Available online at: www.isroset.org

Received 29/Dec/2017, Revised 11/Jan/2018, Accepted 05/Feb/2018, Online 28/Feb/2018

\begin{abstract}
Health is a major concern of today's age. The development of information technology and computing changes the entire arena of life and the gradual development became responsible for the emergence of Digital Society. Information Technology is about the collection, selection, organization, processing, management and dissemination of information and similar contents viz. data and knowledge. For this task and affairs, several information technological tools have been used and it is increasing rapidly. Today it is very difficult to find out an area where utilization of information technology is absence. Hence healthcare is not an exception. Digital Health becomes an important concept these days for the creation of digital health and medical contents. Similar to other areas like Digital Business, Digital Marketing, Digital Education, Digital Health become a concept and key strategy for the development and modernization of healthcare affairs powered by Information Science and Technology. The integration and combination of information technology and computing create a separate domain and branch called 'Health Information Science'. However, it is important to note that it is also known as Health Informatics nomenclature in the line of UK based academic units. Initially, the branch was mainly popular in the western countries and developed countries but gradually it is rising as a branch of study in a country like India. Private universities in India are rapidly increasing and the growth, initiative of private initiative is noticeable. This paper is conceptual in nature and deals with aspects of Health Informatics including its growing trends as a program of study in private universities in India.
\end{abstract}

Keywords - Health, IT, Computing, Health Information Systems, India, Developing Countries, Curricula, Private Universities, MSc Health Informatics.

\section{INTRODUCTION}

Health Informatics is a field and technologies responsible for the collection, selection, organization, processing, management, and dissemination of health related information with the help of tools, techniques and technologies. Health Informatics is also known as Health Information Science. It is important to note that Information Science term popularized in United States and gradually well known in other countries as well [1,5]. As far as Informatics is concerned the term popularized and conceptualized in UK and also used in other countries. Hence both 'Information Science' and 'Informatics' term become popular and same case to case basis. Today Health Informatics becomes important applied science branch of study and useful not only in developed nations but also in developing nations as well. The areas viz. Hospitals, healthcare units, medical diagnostics centre, clinical center, pharmaceutical centers and laboratories, clinical establishments are important clients and utilizing areas of Health Informatics skilled or knowledge products $[2,3,7]$. Universities are offering $\mathrm{BSc}, \mathrm{MSc}, \mathrm{PhD}$, even Post Doctoral Degrees in the field of Health Information Science. In India as well initially only deemed universities offered the program and gradually in recent past, some of the universities started to offer the program on Health Informatics. The growth of private universities is the main reason behind this $[4,6]$. Though, sometimes allied branches are also offered in Health Information Sciences. The Figure 1 shows the basic concept of Health Informatics for enhanced healthcare systems. 


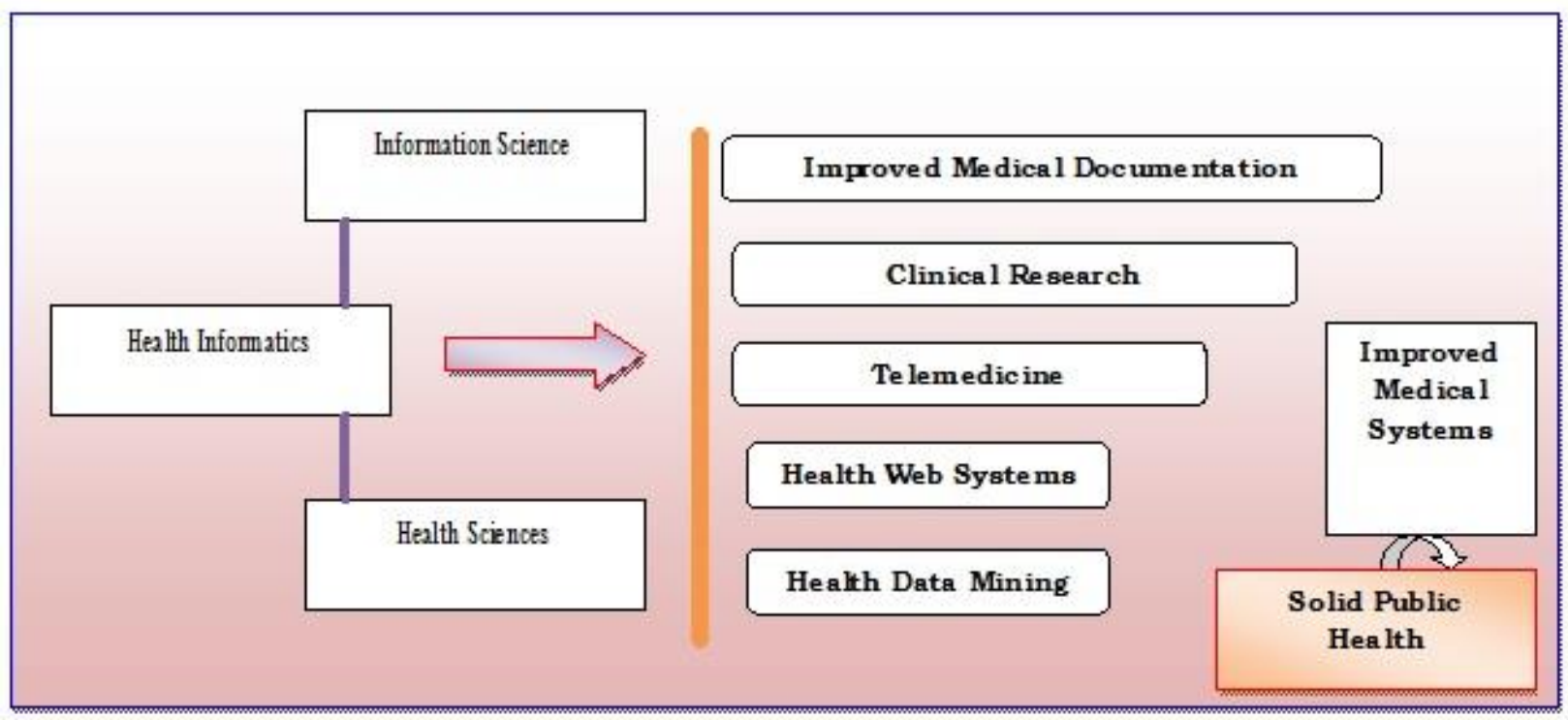

Figure 1. Health Informatics and its core role at a glance(Paul. et al)

\section{OBJECTIVE}

The main aim of this research work is to include the following (should not be confused with only limited to these)-

- To learn about the Health Informatics including its basic,its meaning and characteristics.

- To dig out the core areas of Health Informatics or Health Information Science branches which are emerging rapidly.

- To find out the early days of Health Informatics promotion and development in India in a brief manner.

- To learn about the Health Informatics programs available worldwide and their changing area of specialization.

- To learn about the private universities in India with reference to the institutions of Health Informatics programs.

\section{HEalth INFormatics: The BRANCH AND ALLIED BRANCH}

Health Informatics is a branch of study responsible for design, development and evaluation of health information systems using Information Technological components viz. Database Technologies, Networking Technologies, Multimedia Technologies, Web Technologies, Software Technologies etc. In recent past, it has wide range of uses and utilization areas including Hospitals, healthcare units,
- To dig out the basic of Health Informatics programs in India other than Private Universities.

- To find out the core challenges, issues and the key concern of Health Informatics promotion in India with reference to educational projects.

\section{METHODOLGY}

This is a conceptual and theoretical work and mainly deals to find out of basics of Health Informatics including nature and concept. This is a work dedicated to find out the educational programs in the field of computing and informatics in respect of Healthcare. Here basic literature review has been performed to dig out the latest of Health Informatics and moreover web review has been undertaken in depth to learn about current trends of Health Informatics and allied fields. Moreover, web review has been conducted through the UGC (Govt. of India) official site to learn about the private universities. Such URL has been used to learn about Health Informatics program in Indian universities as well. This study has been conducted during October, 2017 to November, 2017.

medical diagnostics centre, clinical center, pharmaceutical centers and laboratories, and clinical establishments hence apart from the above technologies few more are also using such as;

- Cloud Computing and Technologies

- Big Data Technologies

- Human Computer Interaction Designing

- Usability Experience Designing and Engineering

- Information Security and Assurance etc. 
Gradual development of Health Informatics leads to the new kind of branches such as Nursing Informatics, Dental Informatics, and Public Health Informatics. The mature rate of big data technologies into healthcare systems leads Health Data Science. The following are the basic of informatics in respect of healthcare segment.

Nursing informatics: is a merging domain combined with nursing science and also computing or information systems. Identification, define, manage, communication of data and information with adequate tools, technologies are the core of this field and practicing area. The key stakeholders of the domains include Nurses, consumers, patients, physician, and also other healthcare team for the creation of better and healthy healthcare systems and transparent nursing systems. There are many definitions given by many concerned organizations and few of them are include-

- NI supports nurses, consumers, patients, the interprofessional healthcare team, and other

Dental Informatics: Dental Informatics is a practicing domain and also emerging as a field of study responsible for the collection, organization, and dissemination of information related to dental sciences. It is emerging as an area of knowledge within Health Information Sciences. It is the key for the new age, modern dentist, and dental houses to keep records related to the dentistry $[7,11]$.

The advancement of information and communication technology led the development of more faster and efficient systems and among them Data Science is important one for sorting data and information among the large amount of data and complex data. Hence the concept of Health Data Science has been arrived in recent past.

Health Data Science is the combination of following;

- Information Science and Technology (i.e. Computer Science, Information Studies, Information Technology, Computing, Management Information Systems)

- Health and Medical Sciences (includes Health Science, Medicine, Dentistry, Pharmacy, Regenerative Medicine etc.)

- Mathematical Sciences (includes Mathematics, Statistical and Actuarial Sciences)

- Management Science (include Management principles, Commerce etc.)

\section{GROWING HEALTH INFORMATICS, INDIA \& ACADEMIA}

Health Informatics initiative in India has been started in the year 1960's and the core initiative has been taken since 1970 . stakeholders in their decision-making in all roles and settings to achieve desired outcomes. This support is accomplished through the use of information structures, information processes, and information technology (Official Site, HIMSS, 2016).

- Nursing Informatics is the "science and practice (that) integrates nursing, its information and knowledge, with management of information and communication technologies to promote the health of people, families, and communities worldwide." (IMIA Special Interest Group on Nursing Informatics 2009). The application of nursing informatics knowledge is empowering for all healthcare practitioners in achieving patient centered care (American Medical Informatics Association, 2016 Official Site).

With the initiation of MEDLINE in 1991 India started its journey in Health Informatics journey. The Health Literature, Library and Information Service (HELLIS) later on were established in the year 1979 in India. The most major computing and informatics establishment from the government level in India was National Informatics Centre (NIC) and it has played a great role for the progress of health information development. Later on, the MEDLINE was a great development in the health related database. The joint venture of ICMR-NIC was noted in the year $1986[9,10]$.

The National Informatics Centre later (in 1993) again started with the nomenclature as Health Information Network having over 200 centers. Within a short span of time the collection reached to 160 countries. The main benefit of this project wasthe collection of bibliographical data in health and medical affairs. Later on,it also offers the full text data as well as also the internet facilities.After few years the progress of the Medical and Health Informatics was also started and that time National Medical Library establishment was a milestone. These health informatics initiatives helped a lot in progress and betterment of services to the medical colleges, hospitals, clinical centers, dental centers and so on $[8,11]$. Gradually later on some of the universities have started the initiative for offering Health Informatics as a program of study. Initially, some universities started to offer a paper or course and gradually full-fledged Masters Degree as well. Among the initiative first was taken by the Manipal University, Karnataka with a degree of MSc. Later Amrita Institute of Medical Sciences, Amrita University, Tamilnadu and others have started different kind of Health Informatics programs (detail has been listed in Table: 1). 
Table 1. Different Health Informatics academic program (other than private universities) Academic Programs in Health Informatics

\begin{tabular}{|c|c|}
\hline \multicolumn{2}{|c|}{ Academic Programs in Health Informatics } \\
\hline $\begin{array}{c}\text { Amrita Institute of Medical Sciences, Amrita } \\
\text { University, Tamilnadu }\end{array}$ & MSc in Medical Informatics \\
\hline $\begin{array}{c}\text { College of Allied Sciences, Manipal } \\
\text { University, Manipal, Karnataka }\end{array}$ & MSc in Health Informatics \\
\hline $\begin{array}{c}\text { College of Allied Sciences, Manipal } \\
\text { University, Manipal, Karnataka }\end{array}$ & MBA- Health Information Administration \\
\hline $\begin{array}{c}\text { Public Health Foundation of India (Indian } \\
\text { Institute of Public Health), Hyderabad }\end{array}$ & MSc-Health Informatics \\
\hline $\begin{array}{c}\text { MedVarsity (in association with Applo } \\
\text { Group of Hospitals) }\end{array}$ & Post Graduate Diploma in Medical Informatics \\
\hline $\begin{array}{c}\text { Amrita Institute of Medical Sciences, Amrita } \\
\text { University, Tamilnadu }\end{array}$ & Post Graduate Diploma in Medical Informatics \\
\hline $\begin{array}{l}\text { Osmania University, Telangana } \\
\text { Post Graduate Diploma in Medical Informatics } \\
\text { (Advanced) }\end{array}$ \\
\hline
\end{tabular}

In India, only a few universities started Health Informatics programs with majorly MSc degree while few offered Post Graduate Diploma program in the areas of Health Informatics while one offered MBA program in the Health Informatics in the line of universities abroad. Internationally Health Informatics is a popular program of study(such as BS, MS, BSc, MSc, MNS-Nursing Informatics etc.) in different universities around the world viz.

- University of Victoria,

- Swansea University,

- University of Sheffield,

- University of Central Lancashire,

- Nova South Western University,

- University of Limerick,

- University of West London,

- City University of London,

- University of Alabama at Birmingham,

- University of Toronto,

- Dalhousie University,

- University of London,

- Boston University,

- The Hong Kong Polytechnic University,

- Kingston University of London,

- National University, Canana

- University of Miami

The programs internationally available as a collaborative in association with the industries and organizations study with programs of Masters Degree, Bachelors Degree, Post Graduate Diploma, Diploma, and Certificate Programs. However, many universities are also offering Doctoral Degrees leading to $\mathrm{PhD}$.

\section{HEALTH INFORMATICS AND ITS NEED WITH RefERenCe to Private Universities: The GROWING INDIA}

Health informatics is the combination of knowledge, skills, as well as tools that help in information to be collected, managed, delivery of medical as well as healthcare services and also promoting healthcare services. Healthcare is actually one of the growing segments where information technology and computer science helps in ensuring better efficiency. In generally we may call the application of information technology etc for solving the problems in the field of healthcare and medicine. Ultimately Health Informatics helps to reduce cost and also increasing efficiency for the promotion and development of new healthcare concepts and services.

Internationally healthcare and life sciences market is increasing and will reach $\$ 10.8$ trillion within 2020 for the ultimate promotion of the e-health and preventative healthcare the highest growth areas. According to the sources in 2014 (worldwide), Healthcare IT opportunity is about $\$ 46.7 \mathrm{~B}$ and by 2020 the medical information will binary (double)in every 73 days. As per latest study United States is the biggest healthcare market by size but gradually other areas of the globe moving for a better position. Healthcare industry has the potentiality to reach out the inefficiency and as a result like developing countries in India also a better tomorrow is awaiting for. Most countries which include developing like India and developed are in shortage of skilled healthcare manpower.

Health Informatics has a wide range of application and opportunities in healthcare settings and organizations viz. 
- Shift from the paper-based processes to the electronic processes for the creation of electronic medical / health records.

- Health Informatics is responsible for reducing cost in the Healthcare settings in future context and also for reducing complexity.

- $\quad$ Lack of and minimum qualified information technology professionals needed for Healthcare automation and modernization.

- Health Informatics professionals build deep and healthy healthcare domain knowledge in diverse areas viz. healthcare standards, applications, workflows, and regulations.

- New technologies in Information Technologies are increasing viz. mobile, cloud computing, web technologies, and advanced $\mathrm{BI} /$ analytics and all these may be utilized with Health Informatics degree/ professionals.

- Strong global demand for experienced Health Informatics professionals both in India and overseas is another core reason for the development of educational programs in the field.

Hence career opportunities in this healthcare industry are rising rapidly to cater a wide variety of technology skills. The opportunity in healthcare segment is emerging and to be a healthcare professional one no need for a medical degree holder. Even traditional IT and computing degree holders are not suitable in many cases.
Apart from Health Informatics technical skills, another set is called Health Information Management where one can work as IT managers in Hospitals and Healthcare organizations and institutions. Graduates from the diverse background can opt for the specialization in Health Information Technology.

Due to the ample job opportunities the IT managers and leaders in the hospitals, healthcare focused IT firms, medical device solutions firms, etc universities moving towards Health Informatics degree and programs. There apart from bio and medical focused degree holders viz. MBBS, BSc/MSc Nursing, BDS, MDS, BPharm, MPharm, the technical graduates such as BE/BTech are eligible for application. Moreover, students from other branches viz. $\mathrm{BBM} / \mathrm{BCom}, \mathrm{BCA} / \mathrm{BSc} / \mathrm{BA}$, etc can also move to Health Informatics program.

Here one statement of Steve Ballmer (Former CEO, Microsoft) is useful to learn about the status and importance of Health Informatics "The number one issue we face in health care is keeping quality high while reducing costs. Moving medical records online will improve the way healthcare is delivered - computing will deliver greater efficiency to medicine."

Moreover, job title wise Health Informatics has numerous opportunities worldwide even in developing countries like India. Some of the possible job opportunities and titles as prescribed by the reputed MGUMST, an institute of excellence in Health Informatics are listed in Table: 2.

Table 2. Different Health Informatics job opportunities

\begin{tabular}{cc}
\hline Consultant & Health Informatics Director \\
\hline Academic - Faculty, Teacher & Clinical Data Analyst \\
\hline Clinical Project Manager & Chief Technology Officer \\
Informatics Nurse & Transcription \\
\hline Health Record Manager & Clinical Informatics Manager \\
\hline Trainer- Healthcare & Clinical Coding \\
\hline Project Officer-HIT/ Healthcare & Patient Information Assistant \\
\hline Implementation Manager & Health IT/ System Architects \\
\hline
\end{tabular}


Worldwide Higher Educational Institutes are rising, universities are moving towards the new type of courses which are skillful, interdisciplinary, value-added, industry rated. As far as Higher Educational Institutes are concerned India holds the highest number of educational institutes in the world i.e. with over 40000 (forty thousand). And the number is rising day by day, most of these universities are engaged to offer new age program and here private universities are doing a wonderful job. In the last decade, private universities have increased in a rapid manner and today 279 universities in this segment offering educational services to the nation and society. Details of Higher Educational Institutes (HEIs) have been listed in Table: 3

Table 3. Various kinds of Universities in India: A Snapshot

\begin{tabular}{|c|c|c|}
\hline Universities & In Numbers & Location \\
\hline Central Universities & $\mathbf{4 7}$ & Pan India with 28 States and UT \\
\hline State Funded Universities & $\mathbf{3 7 0}$ & Pan India with 28 States and UT \\
\hline State Private Universities & $\mathbf{2 9 0}$ & Except some states and UT \\
\hline Deemed Universities & $\mathbf{1 2 3}$ & Except some states and UT \\
\hline
\end{tabular}

Private universities in India are rising, most of the states having this kind of educational institutions except Tamilnadu, Kerala, Goa, Jammu \& Kashmir etc. Number wise Rajasthan holdsthe first position being the highest number of private universities (46), while UP and MP hold second and third position with the number of institutions of 29 and 24 respectively.

Table 4. Private Universities in India (State Wise, as on October, 2017)

\begin{tabular}{|c|c|c|}
\hline Serial No. & States & No. of Universities \\
\hline 1 & Arunachal Pradesh & 7 \\
\hline 2 & Assam & 5 \\
\hline 3 & Bihar & 2 \\
\hline 4 & Chhattisgarh & 9 \\
\hline 5 & Gujarat & 30 \\
\hline 6 & Haryana & 20 \\
\hline 7 & Himachal Pradesh & 17 \\
\hline 8 & Jharkhand & 7 \\
\hline 9 & Karnataka & 14 \\
\hline 10 & Meghalaya & 8 \\
\hline 11 & Mizoram & 1 \\
\hline 12 & Madhya Pradesh & 24 \\
\hline 13 & Maharashtra & 9 \\
\hline 14 & Manipur & 1 \\
\hline 15 & Nagaland & 3 \\
\hline 16 & Odisha & 4 \\
\hline 17 & Punjab & 15 \\
\hline 18 & Rajasthan & 46 \\
\hline
\end{tabular}




\begin{tabular}{|c|l|c|}
\hline 19 & Sikkim & 5 \\
\hline 20 & Tripura & 1 \\
\hline 21 & Uttar Pradesh & 29 \\
\hline 22 & Uttrakhand & 13 \\
\hline 23 & West Bengal & 9 \\
\hline & Grand Total & $\mathbf{2 7 9}$ \\
\hline
\end{tabular}

important one is Mahatma Gandhi University of Medical Sciences \&

Though India holds a good number of universities and HEIs but it is painful that educational programs whether degree or diploma in Health Informatics offered are comparatively less. Surprisingly not a single Central Universities and State Funded Universities offer the program on Health Informatics. But thanks to deemed universities by whom Health Informatics educational programs initiated in India. However, due to possibilities for better healthcare and a large number of population, many private universities have been started programs in this field. Among these universities, the
Technology, Rajasthan, India which offers a large number of Health Information Science programs ranging from Bachelors, Masters, Post Graduate Diploma and even Certificate Program with the level of Post Graduate Certificate (PGC).

Apart from these programs other academic offerings also exist, details on this may be noted from the Table: 5 .

Table 5. Different Health Informatics programs started in Private Universities in India

\begin{tabular}{|c|c|c|}
\hline \multirow[t]{2}{*}{ SI. No. } & \multicolumn{2}{|c|}{ Health Informatics Program at Private Universities in India } \\
\hline & Universities & Programs \\
\hline \multirow[t]{2}{*}{1} & Institute of Trans-Disciplinary Health & MSc-CS (Health Informatics) \\
\hline & Sciences and Technology University, & Integrated MSc-CS (Health Informatics) \\
\hline 2 & Chitkara University, Punjab & MBA (Health IT) with Fortis \\
\hline \multirow[t]{6}{*}{3} & Mahatma Gandhi University of Medical & BSc-Health Informatics \\
\hline & Sciences \& Technology & MSc-Health Informatics \\
\hline & & PG Certificate in Nursing Informatics \\
\hline & & PG Certificate in Health Informatics \\
\hline & & PG Diploma in Nursing Informatics \\
\hline & & PG Diploma in Health Informatics \\
\hline & University of Petroleum and Energy & BTech-CSE \\
\hline 4 & Studies, UK & (Health Informatics (all with IBM) \\
\hline
\end{tabular}

It is worthy to note that most of these universities offer the program of Health Informatics as a specialization in Engineering, and Management. More clearly the new age MBA in Health Informatics (nomenclature as Health Information Technology) is offered by the Chitkara University, Punjab.

The BTech program which is most common in India now also lies in Health Informatics. Specifically, Health Informatics is offered in the most sought-after, available BTech subject i.e. Computer Science and Engineering
(CSE). This program is offered with the nomenclature BTech-Computer Science and Engineering (Health Informatics). This program is offered by the University of Petroleum and Energy Studies, UK [7, 12].

And importantly this is offered with the technical collaboration and cooperation from the IBM. The details of curricula have been listed in Table: 6 as a token of understanding and clarification in this regard. 
Table 6. Sample course curricula of new age BTech CS with Health Informatics specialization

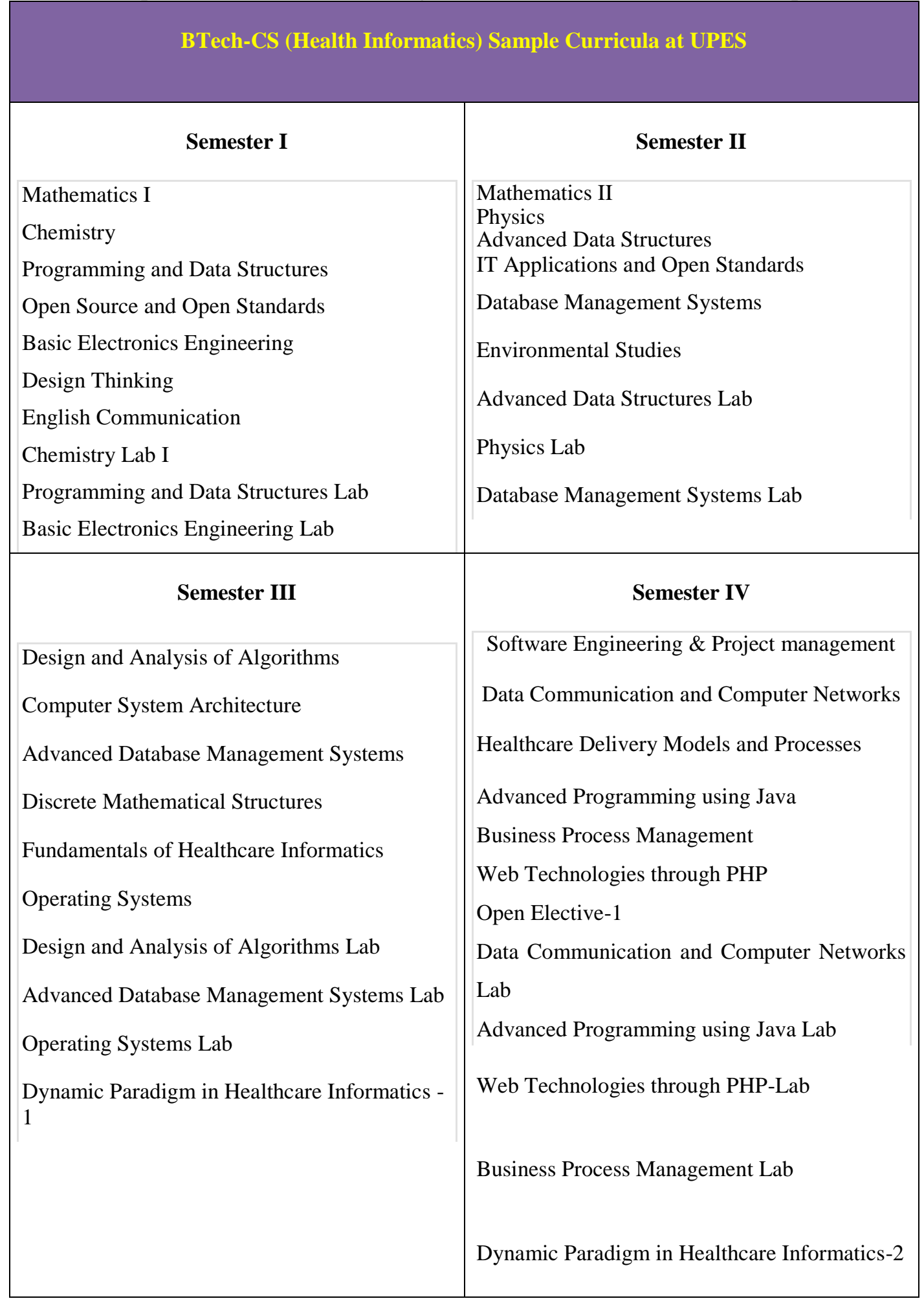




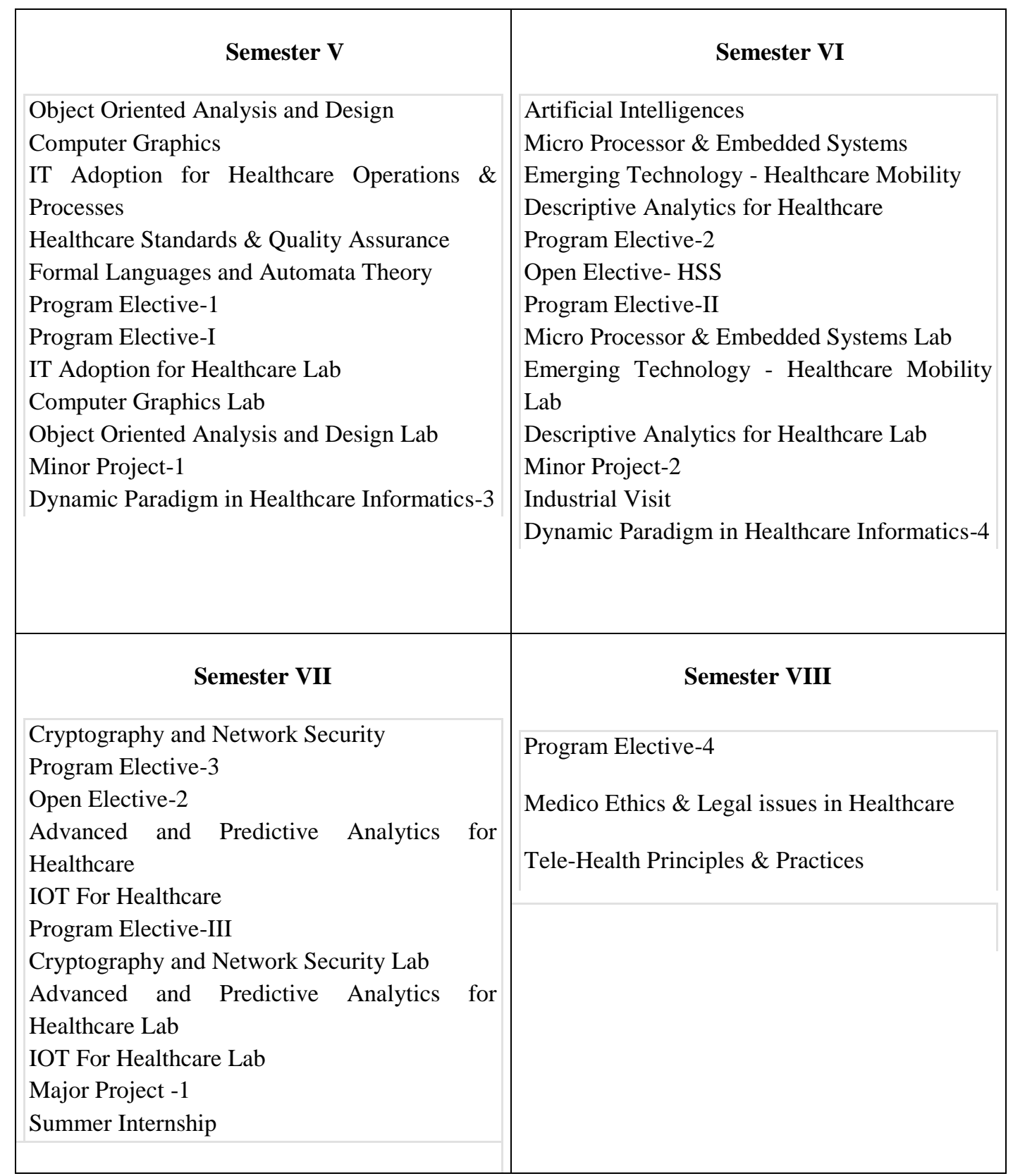

Curricula wise first year deals with general science and technological fundamental contents while from the second year to fourth year the program is offered in the subject Computer Science and Engineering. It is important to note that the specialization of Healthcare Informatics is offered in two way first-Mandatory Papers and second-Elective Papers. Among the Mandatory papers important are include-

- Fundamentals of Healthcare Informatics

- Dynamics Paradigm in Healthcare Informatics Lab I

- Healthcare Delivery Models and Process

- Dynamics Paradigm in Healthcare Informatics Lab II
- IT Adaptation for Healthcare Operations and Process

- Healthcare Standards and Quality Assurance

- IT Adaptation for Healthcare Lab

- Dynamics Paradigm in Healthcare Informatics Lab III

- Emerging Technology-Healthcare Mobility I

- Descriptive Analytics I

- Emerging Technology-Healthcare Mobility Lab I

- Descriptive Analytics Lab I

- Emerging Technology-Healthcare Mobility Lab II

- Descriptive Analytics Lab II

- IoT for Healthcare 
- $\quad$ IoT for Healthcare Lab

- Advanced Predictive Analysis for Healthcare

- Medico Ethics and Legal Issues in Healthcare

- Tele Health Principles and Practice
Whereas apart from these mandatory Health Informatics papers optional four (4) papers / courses are also offered from the list of electives (anyone from each program list). Please refer Table: 7 .

Table 7. List of Program Elective (any four) from BTech-CS (Health Informatics)

\begin{tabular}{|c|c|c|c|}
\hline Program Elective 1 & Program Elective 2 & Program Elective 3 & Program Elective 4 \\
\hline Storage Technology & Information Retrieval \& & Knowledge Management & Health workflow process \\
Foundation & Search Engines & in Healthcare Informatics & analysis \\
Introduction to & Digital Image Processing & Healthcare Research & Maintenance of Health IT \\
Virtualization \& Cloud & Compiler Design & Methods \& Professional & Systems \\
Computing & & Issues & Data Recovery \\
Modeling \& & & Healthcare Usability & \\
Simulation & & Engineering & \\
\hline
\end{tabular}

Hence it is a good move by the private universities not only for offering full-fledged programs and degrees in the areas of Health Informatics but also specialization and major.

\section{FINDINGS AND SUGGESTIONS}

Government taking proper initiative for the promotion of higher education in some context and as a result, various universities are established in recent past and thus such private universities are starting programs in the field of Health Informatics and allied branches. However, it is worthy to mention that following may be noted as an important suggestion in this regard-

- Government needs healthy cooperation and collaboration for smarter Health Informatics environment creation and support from various ministries of the allied branches are highly required viz. Health, Family Welfare and related departments and ministries.

- The NGOs and social welfare organizations and also other Higher Educational Institutes viz. Universities, colleges, research centers required proper initiative for the promotion of Healthcare Systems and here Health Informatics can play a vital role.

- Initially if starting full-fledged Health Informatics programs with BSc, MSc, BBA, MBA, BTech, MTech etc are tough then the specializations in the field may also be offered gradually.

- IT and Healthcare professionals may be engaged in the current Health Informatics projects and also in the contemporary training, seminars, workshop etc for the development of Healthcare systems.

\section{CONCLUSION}

India is suffering from Health Informatics related problems and among the challenges important one includes better and enhanced task management. Less and minimum awareness is another reason for the growth of Health Informatics programs in India. Problems related to funding and finance are also important in India for the solid promotion of healthcare segment and also Health Informatics practices. It is an important move by the private universities regarding the initiation of Health Informatics programs [7], [9]. More importantly, private universities need to offer more programs in the Health Informatics areas and sub fields after gradual development viz. Dental Informatics, Nursing Informatics, Neuro Informatics, Bio Informatics etc. Among the Higher Educational Institutes (HEIs) a good percentage belongs with the Government funded and from that space, the initiatives are very minimum; more clearly not a single university offers the program on Health Informatics. However initially, they may offer the program as a specialization and gradually as a major in the areas of Computer Science, Information Technology, and Information Sciences at the Masters or Bachelors program.

\section{REFERENCE}

[1] Aarts J. Peel V \& Wright G., "Organizational issues in health informatics: a model approach" International journal of medical informatics, Vol. 52, Issue1, pp. 235-242. 1998,

[2] Friede A. Blum H. L, \& McDonald M., "Public health informatics: how information-age technology can strengthen public health"Annual review of public health, Vol. 16. No. 1,pp. 239-252, 1995. 
[3] Haux, R. "Aims and tasks of medical informatics. International journal of medical informatics", Vol. 44. No.1, pp. 9-20, 1997.

[4] Hersh W. R., Juniu K., Mailhot M., \& Tidmarsh P. "Implementation and evaluation of a medical informatics distance education program"Journal of the American Medical Informatics Association, Vol. 8. No. 6, pp. 570-584, 2001.

[5] Hook S. A., "Teaching health informatics: designing a course for a new graduate informatics program"Journal of the Medical Library Association, Vol. 91, No. 4, pp. 490, 2003.

[6] Kun L. G. "Telehealth and the global health network in the 21 st century. From homecare to public health informatics. Computer methods and programs in biomedicine "Vol. 64, No.3, pp. 155-167, 2001.

[7] Paul P.K., "Web 2.0 and Social Networking in Pharmacy and Allied Medical Domain: An overview' 'International Journal of Marketing Theory, Vol. 3, No. 2, pp. 137-143, 2013.

[8] Pau1, P.K., "Web 2.0: emphasizing Pharmacy 2.0/ Pharmaceutical 2.0-Promising Interdisciplinary Information Science Field" Scholars Academic Journal of Pharmacy, Vol. 2, No. 6, pp. 476-480, 2013.

[9] University Grants Commision, www.ugc.ac.in (Accesed several section on $05-08-2016$ )

[10] All India Council for Higher Education, www.aicte-india.org (Accesed several section on 05-08-2016)

[11] Ministry of Human Resource Development, www.mhrd.gov.in (Accesed several section on 05-08-2016)

[12] Health Informatics, https://en.wikipedia.org/wiki/Health_informatics(Accesed on 05-08-2016) 